\title{
COMPLICAÇÕES HEMORRÁGICAS INTRACRANIANAS NA OSTEOGENESE IMPERFEITA
}

\author{
LAERTEL F. FASSONI * \\ MICHEL P. LISON **
}

Apesar de ter sido aventada no começo do século (Eddowes, 1900) a teoria da alteração mesenquimal difusa na osteogênese imperfeita (OI), as descrições se reefrem, em sua maioria, a modificações restritas a poucos elementos do mesênquima, em particular aos osteoblastos, odontoblastos e fibroblastos da esclerótica.

A ocorrência de manifestações neurológicas no decorrer da evolução da OI tem sido verificada em número muito reduzido de pacientes. Tivemos a oportunidade de estudar dois casos com acidente hemorrágico intracraniano espontâneo que julgamos de interêsse relatar.

\section{OBSERVAÇOES}

Caso 1 - A. C. C. F., com 20 anos de idade, sexo masculino (R.G. 5964), procurou o Departamento de Clínica Neurológica em março de 1968, relatando que 26 dias antes apresentara crise convulsiva iniciada por sensação de pêso súbito na cabeça, seguida de perda de consciência, contrações tônico-clônicas generalizadas e incontinência urinária. Passada a crise apresentou cefaléia e vômitos. Medicado, passou bem durante 11 dias, quando apresentou quadro de instalação súbita caracterizado por obnubilação, febre alta, vômitos e rigidez de nuca. Nessa ocasiāo foi feito exame do líquido cefalorraqueano que se apresentou xantocrônico. Antecedentes pessoais e familiares - Aos 10 meses de idade sofreu queda de um degrau, fraturando o fêmur esquerdo. Desde então, apresentou fraturas freqüentes de ambos os fêmures e ossos da perna e braço esquerdos. Aos 10 anos de idade, no Departamento de Clínica Médica, foi submetido aos seguintes exames complementares: no sangue: fósforo inorgânico $5,6 \mathrm{mg} / 100 \mathrm{ml}$; cálcio $10,0 \mathrm{mg} / 100 \mathrm{ml}$; fosfatase alcalina 3,1 unidades Bodansky por $100 \mathrm{ml}$ de sôro. Tempo de sangria 1 minuto e 5 segundos. Tempo de coagulação 3 minutos. Eletroforese de proteinas séricas: aumento de globulina alfa-2 $(0,98 \mathrm{~g} / 100 \mathrm{ml})$. Nessa oportunidade foi feito o diagnóstico de OI. A moléstia, pelas deformidades dos membros supe-

Departamento de Clinica Neurológica da Faculdade de Medicina de Ribeirão Prêto da Universidade de São Paulo (Prof. J. Armbrust-Figueiredo): * Médico residente; ** Professor Assistente. 
riores, inferiores e do tórax, incapacitou-o progressivamente. Há dois anos diminuição da acuidade auditiva. Não há caso semelhante na familia. Exame clínico-neurológico - Por ocasião da internação o exame mostrava paciente com deformidades ósseas dos 4 membros e do tórax; escleróticas azuis; pressão arterial 11-7. Não havia rigidez de nuca. Fundos oculares normais. Exames complementares - Hemograma: 4.000.000 eritrócitos por $\mathrm{mm}^{3} ; 11,7 \mathrm{~g}$ de hemoglobina; 6.000 leucócitos por $\mathrm{mm}^{3}$. Tempo de sangria 4 minutos. Tempo de coagulação $2 \mathrm{minu-}$ tos e 30 segundos. Tempo de protrombina $100 \%$ do normal. No sangue: cálcio $10 \mathrm{mg} \%$; fósforo $3,5 \mathrm{mg} / 100 \mathrm{ml}$; fosfatase alcalina 3,3 unidades Bodansky por $100 \mathrm{ml}$ de sôro. Radiografias do crânio: desmineralização das tábuas ósseas; platibasia; abaulamento do osso occipital; vértice ponteagudo; pineal calcificada, de topografia normal. Radiografias da coluna vertebral: osteoporose difusa; escoliose da coluna torácica com concavidade superior para a direita; vértebras bicôncavas. Radiografias da bacia e dos membros inferiores: bacia estreitada; coxa vara bilateral; pino metálico intramedular no fêmur direito. Eletrencefalograma: menor organização da atividade de fundo em áreas anteriores do hemisfério cerebral direito e sinais de foco epileptógeno em ambas as áreas fronto-temporais. Carotidangiografia: aneurisma do complexo artéria cerebral anterior direita-artéria comunicante anterior (Fig. 1).
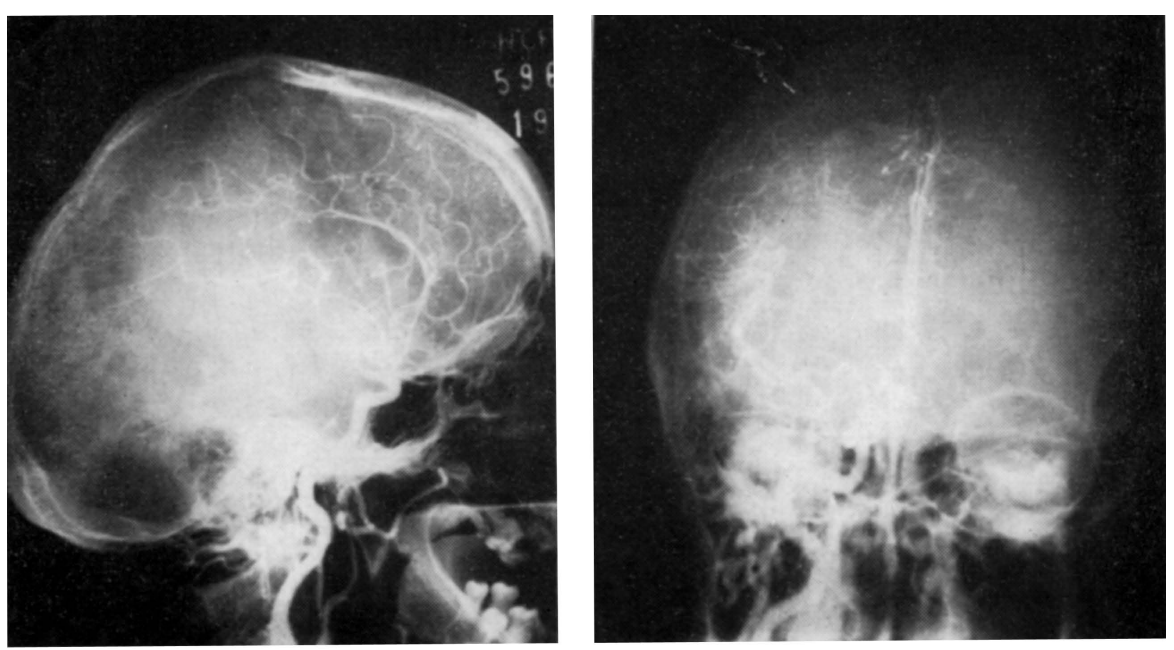

Fig. 1 - Caso 1. Carotidangiografia direita: aneurisma do complexo artéria cerebral anterior direita-artéria comunicante anterior; platibasia; desmineralização das tábuas ósseas; deformidade da calota craniana.

Caso 2 - A. S. M., 20 anos de idade, sexo feminino, branca (R.G. 85.677), procurou o Departamento de Clínica Neurológica, em novembro de 1967, queixando-se de cefaléia frontal, pouco intensa, diária, cujo início ocorreu cêrca de 4 meses antes da consulta. Três meses e meio após, houve exacerbação dẻsse sintoma e aparecimento de vômitos ocasionais. Os familiares notaram alteração do senso crítico. Nega convulsões e traumatismos cranianos. Antecedentes pessoais $e$ familiares - Aos 6 anos de idade, fratura do fêmur direito, complicada por osteomielite. Há 5 anos, apendicite aguda e cesárea de feto inviável de 5 meses. Há 
3 anos, fratura do fêmur direito ao cruzar a perna (sic). Teve duas fillhas; uma sadia e outra com malformação vascular e cujo quadro clínico será apresentado após o relato dêste caso. Dois irmãos apresentam escleróticas azuiz e, um dēles, crises convulsivas. Refere que dois tios são surdos e um sobrinho tem crises convulsivas. Exame clinico-neurológico - Bom estado geral. Paciente apática, indiferente ao meio. Escleróticas azuis. Pressão arterial 11-7. Exame neurológico por ocasiāo da internação em 20 de novembro de 1967, normal. Exames complementares - Hemograma: 4.160.000 eritrócitos por $\mathrm{mm}^{3}$; 7.650 leucócitos por $\mathrm{mm}^{2}$ ( $4 \%$ de neutrófilos bastonetes, $45 \%$ de neutrófilos segmentados; $10 \%$ de eosinófilos; $38 \%$ de linfócitos; $3 \%$ de monócitos); 350.000 plaqeutas por $\mathrm{mm}^{3}$; eritrócitos e plaquetas sem alterações. No sangue: uréia $16,8 \mathrm{mg} / 100 \mathrm{ml}$; cálcio 10,2 mg/ $100 \mathrm{ml}$; fósforo inorgânico $3,4 \mathrm{mg} / 100 \mathrm{ml}$; fosfatase alcalina 3,6 unidades Bodansky por $100 \mathrm{ml}$ de sôro; proteínas totais $6,7 \mathrm{~g} / 100 \mathrm{ml}(4.7 \mathrm{~g}$ de albumina e $2,0 \mathrm{~g}$ de globulina). Reações sorológicas para lues e moléstia de Chagas não reagentes. Tempo de sangria 9 minutos. Tempo de coagulacão 4 minutos. Prova de retracâo do coágulo: normal. Tempo de protrombina $100 \%$ do normal. Prova do laço negativa. Exame do liquido cefalorraqueano: xantocromia em 22-11-67 e normal em 29-11-67. Eletrencefalograma: sofrimento cerebral fronto-temporal esquerdo e, menos intenso, frontal direito. Carotidangiografia: desvio da artéria cerebral anterior esquerda para o lado obosto (Fig. 2).

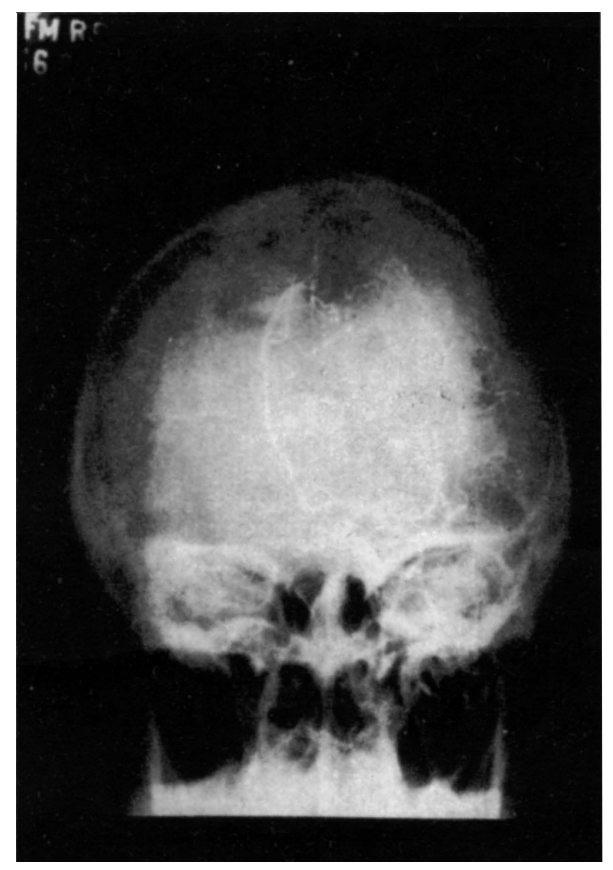

Fig. 2 - Caso 2. Carotidangiofrafia esquerda: desvio da artéria cerebral anterior esquerda.

$\mathrm{Na}$ enfermaria houve agravamento do quadro, com aparecimento de hipoestesia dolorosa, hemiparesia discreta e hiporreflexia osteotendinosa a direita. Trépano-punção exploradora (19-12-67) revelou hematoma subdural fronto-parietal esquerdo, que fol esvaziado. Após o ato operatório ocorreu crise convulsiva lateralizada à direita. Alta hospitalar, em fins de dezembro, com regressão total da sintomatologia. Reinternada em 9-1-68, pois uma semana após a alta reapareceram os mesmos sintomas. Realizada punção exploradora, nôvo hematoma foi esvaziado. Alta em 21-1-68. 
A filha desta paciente, L. M., foi atendida no Departamento de Pediatria (R.G. 49.717), em setembro de 1964, aos 10 meses de idade. Apresentava, desde - nascimento, escleróticas azuis, manchas vinhosas com limites nítidos (na face, pescoço, tronco, membros superiores, porçāo superior da coxa esquerda e região plantar do pé esquerdo), veias superficiais dilatadas no abdome e tórax (Fig. 3). Ao exame, além das alterações já mencionadas, o fígado foi palpado a um dedo do rebordo costal e o baço na fossa iliaca esquerda. Ausência de edema ou ascite. Exames complementares - Hemograma: 3.200 .000 eritrócitos por $\mathrm{mm}^{3} ; 9.400$ leucôcitos por $\mathrm{mm}^{3} ; 6,6 \mathrm{~g}$ de hemoglobina. No sangue: fósforo $4,76 \mathrm{mg} / 100 \mathrm{ml}$; fosfatase alcalina 2,74 unidades Bodansky por $100 \mathrm{ml}$ de sôro; cálcio $8,3 \mathrm{mg} / 100 \mathrm{ml}$; birrirrubina tatal $0,79 \mathrm{mg} / 100 \mathrm{ml}$; colesterol $112,5 \mathrm{mg} / 100 \mathrm{ml}$; uréia $13,2 \mathrm{mg} / 100 \mathrm{ml}$; creatinina $0,9 \mathrm{mg} / 100 \mathrm{ml}$; proteinas totais $5,4 \mathrm{mg} / 100 \mathrm{ml}(3,0 \mathrm{~g}$ de albumina e 2,4 de globulinas). Eletroforese de proténas séricas - aumento de globulina alfa-1 $(0,50 \mathrm{~g} / 100 \mathrm{ml})$ e de globulina alfa-2 $(0,24 \mathrm{~g} / 100 \mathrm{ml})$. Tempo de protrombina 52\% do normal. Tempo de sangria 10 minutos e 30 segundos. Tempo de coagulação 1 minuto e 15 segundos. Esplenoportografia normal. Não foi possivei realizar cavografia por problemas técnicos. Alta hospitalar a pedido dos familiares. Impressões diagnósticas nessa ocasião: osteogênese imperfeita, hemangiomas planos e provável malformação da veia cava inferior. Após a alta apresentou,

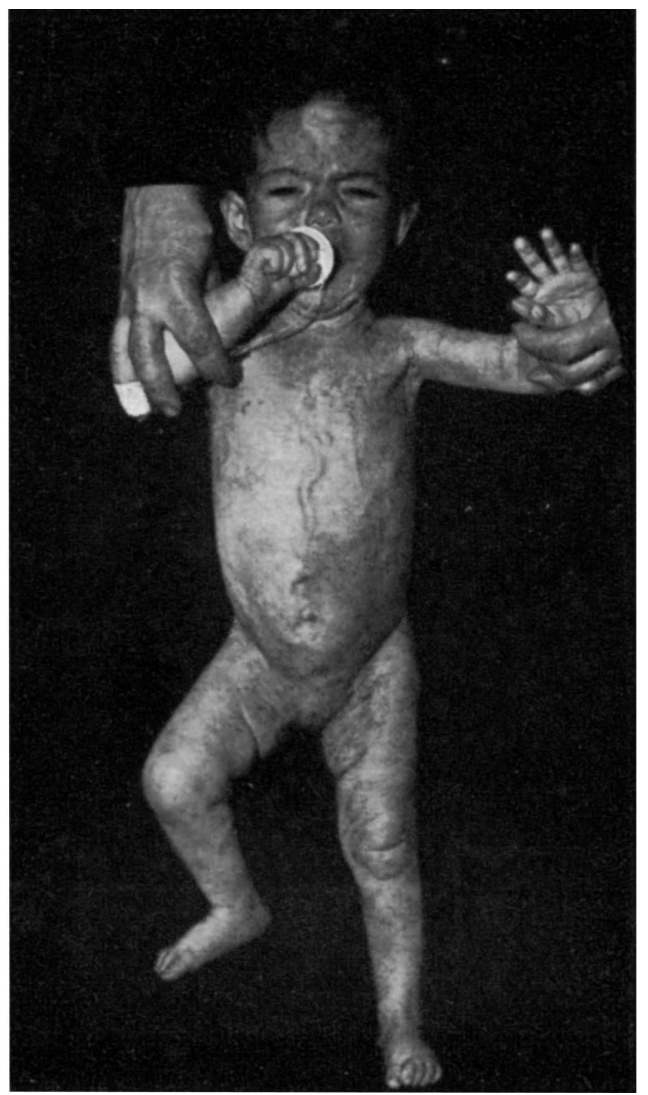

Fig. 3 - Fotografia da filha da paciente A. S. M. (caso 2) mostrando extensos hemangionas planos e dilatação das veias superficiais tóraco-abdominais. 
por três vêzes, crises convulsivas lateralizadas à đireita. Em dezembro de 1967, após queda, apresentou várias crises convulsivas seguidas por distúrbios de consciência. Obito, 18 dias após, em seu domicilio, o que impediu o esclarecimento definitivo do caso.

\section{COMENTARIOS}

Alterações vasculares têm sido esporàdicamente relatadas em pacientes com OI. As anormalidades encontradas incluem hipertrofia generalizada da elástica das pequenas artérias e sinais de artèriosclerose dos vasos tireoídeos em feto de 7 meses (Bauer, 1923); anormalidades da média com irregularidades segmentares das paredes vasculares e formação aneurismática ao nível da artéria renal direita, em lactente falecido após rotura espontânea dessa malformação (Kaul, 1939); insuficiência aórtica secundária à dilatação da raiz dêsse vaso, bem como lesões das válvulas pulmonar, aórtica e mitral, além de alteraçōes microscópicas da parede das artérias pulmonar e aórtica, em dois adultos (Criscitiello e col., 1965). Malformação dos vasos intracranianos foi referida em um paciente com OI tardia, sob a forma de angioma arteriovenoso, estendendo-se pelos hemisférios cerebrais, hemisférios cerebelares e tronco cerebral (Schürmeyer e Isfort, 1963).

A associação de OI com diátese hemorrágica de tipo trombastenia hereditária e familiar de Glanzmann foi assinalada pela primeira vez por Gautier e Guinard-Daniol, em 1952. Estes autores consideram que a ocorrência simultânea das duas afecções poderia ser uma simples coincidência. Contudo, Siegel e col. (1957), ao relatarem um caso semelhante, acreditam na possibilidade de um defeito congênito envolver dois tecidos de origem mesenquimatosa: o tecido ósseo e os trombócitos.

Apesar das alterações vasculares e da diátese hemorrágica de Glanzmann terem sido descritas, sangramento intracraniano, associado a OI, foi referido apenas em um recém-nascido que apresentava várias fraturas nos membros e tórax e cuja necrópsia revelou hematoma subdural de grande volume, com pequeno extravazamento de sangue para o espaço subaracnóideo (Katsampes e col., 1950). Tais achados não foram comentados peJos autores.

No primeiro caso aqui relatado, o quadro clinico e laboratorial de hemorragia meníngea levantou a suspeita de rotura de malformação vascular intracraniana. A carotidangiografia direita revelou um aneurisma arterial do conplexo da artéria cerebral anterior-artéria comunicante anterior, o que justifica, a nosso ver, o diagnóstico de "osteoangiogenesis imperfecta" de acôrdo com o critério estabelecido por Kaul (1939). O achado angiográfico aliado à menor organização da atividade de fundo, nas projeções anteriores do hemisfério cerebral direito, ao exame eletrencefalográfico, são dados sugestivos de rotura de malformação arterial, situada no porção anterior do polígono de Willis. 
O quadro clínico apresentado pelo segundo paciente merece alguns comentários. O estabelecimento progressivo de síndrome de hipertensão intracraniana e de sinais de comprometimento do hemisfério cerebral esquerdo, trouxe e suspeita de um processo expansivo. A carotidangiografia confirmou tal susepita mas sòmente após trepanação exploradora, foi feito diagnóstico de hematoma subdural. Nos antecedentes próximos ou remotos não havia referências a traumatismo craniano ou a fenômenos hemorrágicos.

A possibilidade do sangramento subdural ser motivado por uma diátese hemorrágica de tipo trombastenia de Glanzmann deve ser afastada, pois a prova da retração do coágulo foi normal. Contudo, apesar da normalidade da prova do laço, o aumento do tempo de sangria sugere hemorragia devida a alterações das paredes dos vasos. Embora os exames realizados não tenham evidenciado anormalidades vasculares intracranianas é de grande interêsse lembrar que a primeira filha da paciente apresentava malformações vasculares, associadas a quadro clínico de OI congênita. Estas malformações consistiam em hemangionas planos extensos e em provável anomalia da veia cava inferior. Não temos conhecimento de alterações semelhantes em outros casos de OI descritos na literatura. Esses achados estão de acôrdo com o conceito de doença mesenquimatosa difusa, que envolve em particular o sistema vascular, justificando a denominação "osteoangiogenesis imperfecta".

As anormalidades do sistema circulatório na OI não são inesperadas, desđe que, em outras moléstias hereditárias em que há comprometimento de tecidos de origem mesenquimatosa, elas têm sido assinaladas com freqüência. Na sindrome de Marfan e na síndrome de Ehlers-Danlos, em particular, anormalidades cardiovasculares são comuns.

Esta primeira referência à presença de aneurisma arterial intracraniano em pacientes com OI (caso 1) não constitui achado isolado nesse grupo de moléstias, pois já existe relato de aneurisma da artéria carótida interna em doentes com "pseudo-xanthoma elasticum" (Dixon, 1951).

As carotidangiografias e a trépano-punção exploradora foram realizadas pelo Dr. Nelson Martelli.

\section{RESUMO}

São descritas complicaçōes hemorrágicas intracranianas em dois pacientes com osteogênese imperfeita. Sangramento espontâneo ocorreu no espaço subaracnóideo em um dos pacientes e no espaço subdural, no outro.

Os achados clínicos e paraclínicos são discutidos à luz de um distrbio mesenquimatoso difuso semelhante ao que caracteriza as demais moléstias hereditárias do mesênquima. 


\section{SUMMARY}

Intracranial hemorrhagic complications in cases of osteogenesis imperfecta

The intracranial hemorrhagic complications in two patients with osteogenesis imperfecta are described. Spontaneous bleeding into the subarachnoid space occurred in one patient and into the subdural space in another. The clinical findings and their relationship to a generalized disturbance of mesenchymal tissue are discussed.

\section{REFERENCIAS}

1. BAUER, K. H. - Erbkonstitutionelle "Systemerkrankungen" und Mesenchym. Klin. Wschr. 2:624, 1923.

2. CRISCITIEllo, M.; RONAN, J. A.; BESTERMAN, E. M. M. \& SCHOENWETTER, W. - Cardiovascular abnormalities in osteogenesis imperfecta. Circulation 31:255, 1965 .

3. DIXON, J. M. - Citado por CRISCITIELlo e col. ${ }^{2}$.

4. EDDOWES, A. - Citado por SCHÜRMEYER e ISFORT ${ }^{8}$.

5. GAUTIER, P. \& GUINARD-DANIOL, J. - Un cas de maladie de Lobstein associée a une thrombasthénie heréditaire et familiale de Glanzmann. Bull, et Mém. Soc. Méd. Hôp. Paris, 68:577, 1952.

6. KATSAMPES, C. P.; LEVIN, C. M. \& RASMUSSEN, L. B. - Osteogenesis imperfecta. Med. Radiol. Photogr. 26:60, 1950

7. KAUL, B. - Ein Abortivfall von Osteogenesis imperfecta congenita kombiniert mit Missbildungen der Blutgefässe. Frankfurt Ztschr. Path. 53:287. 1939.

8. SCHÜRMEYER, E. \& ISFORT, A. - Osteogenesis imperfecta tarda EkmanLobstein mit diffuser Hirngefassmissbildung (Osteoangiogenesis imperfecta). Langenbecks Arch. Klin. Chir. 302:449, 1963.

8. SIEGEL, B. M.; FRIEDMAN, I. A.\& SCHWARTZ, S. O. - Hemorrhagic disease in osteogenesis imperfecta. Study of platelet functional defect. Am. J. Med. $22: 315,1957$.

Departamento de Neurologia - Faculdade de Medicina de Ribeirão Prêto Ribeirão Prêto, SP - Brasil. 